\title{
Targeted Cancer Diagnostic and Therapeutic Agents: Delivery by Carriers or Conjugation
}

\author{
Mohsen Mohammadgholi ${ }^{1}$, Farzaneh Rezazadeh ${ }^{1}$, Nourollah Sadeghzadeh ${ }^{1 *}$ \\ ${ }^{1}$ Department of Radiopharmacy, Faculty of Pharmacy, Mazandaran University of Medical Sciences, Sari, Iran.
}

Received: 11 May 2016

Revised: 15 Jun 2016

Accepted: 28 Jun 2016

Corresponding Author: Nourollah Sadeghzadeh,

Department of Radiopharmacy,

Faculty of Pharmacy, Mazandaran

University of Medical Sciences,

Mazandaran, Sari, Iran.

Tel: +981133543695 .

E-mail:

nourollahsadeghzadeh@yahoo.com

\begin{abstract}
Receptors and proteins are overexpressed in many human cancer cell membranes rather than normal tissues and are considered as the main molecular targets. Specific tumor- targeting molecules which have high affinity for these receptors can be valuable tools as carrier molecules for targeted cancer therapy and imaging. Pharmacokinetics and bioavailability of diagnostic and therapeutic agents are very important. Poor selectivity of cancer therapeutic agents causes toxicity on normal cells that limits maximum effective dose. The Attachment of these agents to macromolecules or their installation on carriers is currently under investigation. This article presents recent developments in the field of targeting agents and introduces different carriers and their applications in the diagnosis and treatment of cancer.
\end{abstract}

Keywords: Cancer diagnosis; Cancer therapy; Biological carrier molecules; Diagnostic agent; Therapeutic agents

Please cite this article as: Mohammadgholi M, Rezazadeh F, Sadeghzadeh N. Targeted Cancer Diagnostic and Therapeutic Agents: Delivery by Carriers or Conjugation. Res Mol Med. 2016; 4 (3): 3-9

\section{Introduction}

Cancer is still one of the major causes of death worldwide. Generally, surgery, chemotherapy and radiation therapy are used for treatment of cancer. There is a balance between division, senescence and differentiation in the healthy cells, but the difference in malignant cell cycle kinetics and gene expression levels make them very susceptible to bombardment with cell proliferative inhibitors or toxic agents. Similarly, normal cells that rapidly proliferate like malignant cells are highly subject to damage by cytotoxic drugs. Bone marrow, hair follicles, and intestinal epithelium have quick turnover which results in more sensitivity to chemotherapeutic agents. Tumor cells consume glucose more than normal cells but have low efficiency and are hypoxic. Hypoxic cells are resistant to radiation whether externally or internally. One of pathophysiological characteristics of tumors is rapid vascularization with poor lymphatic drainage which makes them accessible for targeting agents (1-3). Enzymes (4, 5), receptors $(6,7)$ and factors $(8,9)$ which are more expressed in cancerous cells can be restrained by various inhibitors. Oncogenes can be damaged by DNA cross linkers, resulting in DNA synthesis inhibition and malfunction. Multidrug resistance was also observed in tumor cell population that was exposed to some anticancer drugs. Targeted drug delivery (10), also named smart drug delivery is a method of delivering imaging or therapeutic agents to a patient in a manner that increases the concentration of these agents in some parts of the body compared to others. Several radionuclides can be used to label biomolecules or carrier systems for noninvasive imaging of tumors in single photon emission computed tomography (SPECT) or positron emission tomography camera (PET) $(11,12)$. Researchers were interested to design ${ }^{99 \mathrm{~m}} \mathrm{Tc}$ radiolabeled systems with high target to nontarget biodistribution ratio, high pictorial resolution, appropriate clearance and pharmacokinetic and simple preparation in imaging centers. In this review article, we describe biological and nanocarrier agents as valuable tools for cancer diagnosis and therapy. We 
focus on antibodies, aptamers, polymers, proteins, peptides, nanosystems and aptides.

\section{Antibodies}

Antibodies can be used as a carrier molecule for the delivery of radioisotopes (1), toxins, enzymes, or drugs into tumor sites (Figure1). Monoclonal antibody drug conjugation (mADC) is a better strategy to increase the potency of toxic agents with low molecular weight and clinical activity. Linker stability and suitable antigen selection are also important issues in targeting. ADCs showed high intracellular collection through tight binding to tumor-associated cell surface antigens and long circulation time in the plasma. After complex formation and internalization, cytotoxic agent releases and finally reaches intracellular target. Nonetheless, only small amount of the ADC have ever reached the target cells (13-16). In 2001, Senter and Springer selectively activated anticancer drugs, by monoclonal antibody-enzyme conjugates. Enzymes catalytically convert prodrugs to active drugs in three steps. MAb-enzyme binds to cellsurface antigens in the first step, then the enzyme activates prodrug to drug and eventually drug enters into cell. Reduction of immunogenicity can be the result of this innovation (17). In 2004, Hamblett, Senter, Chace, et al. studied conjugation of monomethylauristatin E (MMAE) to the anti-CD30 monoclonal antibody with eight drug moieties per $\mathrm{mAb}$. Their investigation proved that the therapeutic index has inverse proportion to drug loading per antibody (18). In 2010, Kuroda et al. conjugated a humanized anti-prostate-specific membrane antigen (PSMA) monoclonal antibody (hJ591) to the ribosome-inactivating protein toxin saporin to generate an immune toxin for treatment of prostate cancer (PC). Both in vivo and in vitro studies demonstrated that anti-PSMA immune toxin acts as a therapeutic agent for PC (19).

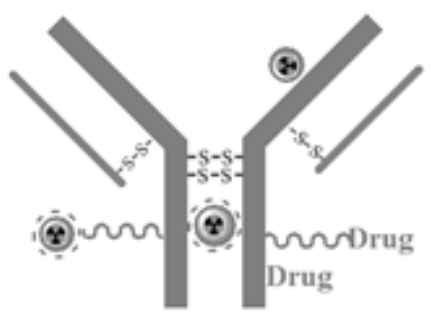

(Radioisotope) um (Linker) (CBelanos)

Figure 1. Antibodies can conjugate to radionuclides or chemotherapic agents whether directly or with linker assistance

Antibodies have been labeled with various radionuclides (RNs) for cancer treatment, but only two radiolabeled anti-CD20 monoclonal antibodies ${ }^{90} \mathrm{Y}$ ibritumomab and ${ }^{131} \mathrm{I}$ - tositumomab are approved by US FDA for treatment of B-cell non-Hodgkin's lymphoma (NHL). Indium-111( $\left({ }^{111} \mathrm{In}\right)$ and ${ }^{99 \mathrm{~m}} \mathrm{Tc}$ are common isotopes used for antibodies labeling for cancer imaging. Because of maladjustment ${ }^{99 \mathrm{~m}} \mathrm{Tc}$ physical half-life and antibody biological half-life, a fragment of antibody is used instead of whole antibody.

\section{Aptamers}

Despite the advantages of antibodies, they have some limitations on clinical use which encouraged the researchers to seek alternatives for antibodies. These limitations include low tissue penetration, immunogenicity, instability and formulation issues, and high manufacturing costs (20). Antibody-based drug delivery may lead to high toxicity due to nonspecific uptake of antibody by Fc normal receptorexpressing cells (21). Aptamers are a class of therapeutic oligonucleotides that form special threedimensional ligand that makes them attractive pharmaceutical agents (22). They bind to their targets with high affinity and demonstrate therapeutic and imaging effect (23) (Figure 2).

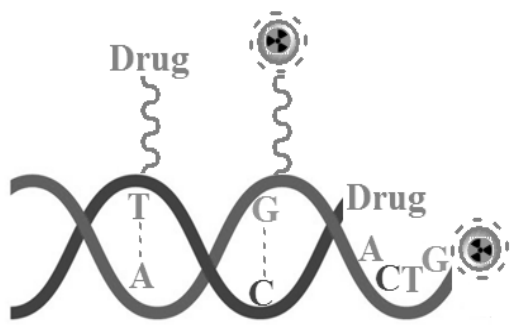

Figure 2. DNA or RNA aptamers can be labeled with radionuclides directly or through linker that is ended to chelating agents. Chemotherapic agents also bind to nucleotide functional groups or linker intercession.

In 2006, Farokhzad and Jon et al. hypothesized that doxorubicin (DOX) may intercalate into the A10 PSMA aptamer and form a physical complex through noncovalent interaction, requiring no modification of the drug or the aptamer. In vitro results displayed stability of the DOX-A10 PSMA aptamer complex in cell culture media and targeted the PSMA-expressing cells with high efficiency (24). In 2009, Tan et al. explored the usage of drug DNA-based aptamer conjugation for targeted drug therapy applications. They used sgc8c aptamer and chose a bifunctional linker to conjugate sgc8c to Doxorubicin. Aptamer conjugated DOX showed high specific binding and affinity to target human T-cell (25). In 2014, Zhao and JianHao, Wei Fan et al. conjugated miR-15a and miR-16-1 aptamers (novel therapeutic ligand against 
PC metastasis) to atelocollagen (purified pepsintreated type I collagen from the calf dermis) that could selectively cause PC cell death in synergic action. In vitro studies in PC3 and LNCaP cell linesby IC50 values revealed that cell growth has been inhibited in a dose-dependent manner. In vivo anticancer efficacy was verified in the human PC bone metastasis mice model (26). Moreover aptamers have been labeled with radionuclide for tumor imaging (1). For example in 2006, Hicke et al. labeled aptamerTTA1 with ${ }^{99 \mathrm{~m}} \mathrm{Tc}$ for malignant tumors imaging (27).

\section{Polymers, proteins and peptides}

One problem about aptamers is that, they need high expression level of target on the cell lines for efficient internalization. Synthesis of oligonucleotides is expensive and has low yield and also cargoe attachment and its optimization need more attention. In addition, there are no clinical data to illustrate feasibility of aptamers' mediation delivery (22). In recent years, short peptides which can target tumorspecific markers (28-33) and water soluble polymers have been used as vehicles for the delivery of anticancer drugs with low molecular weight to tumor tissues (34) (Figure 3). Long circulation time, resistance to enzymatic degradation and low immunogenicity are benefits of polymeric conjugations. Poly ethylene glycol (PEG) as one of the most widely used polymer is inexpensive and has low toxicity, commercially available in various molecular weights and has been approved for internal applications by drug regulatory methods. PEGylated interferon $\alpha-2 b$ and L-asparaginase modified with PEG are two FDA- approved polymeric anticancer drugs.

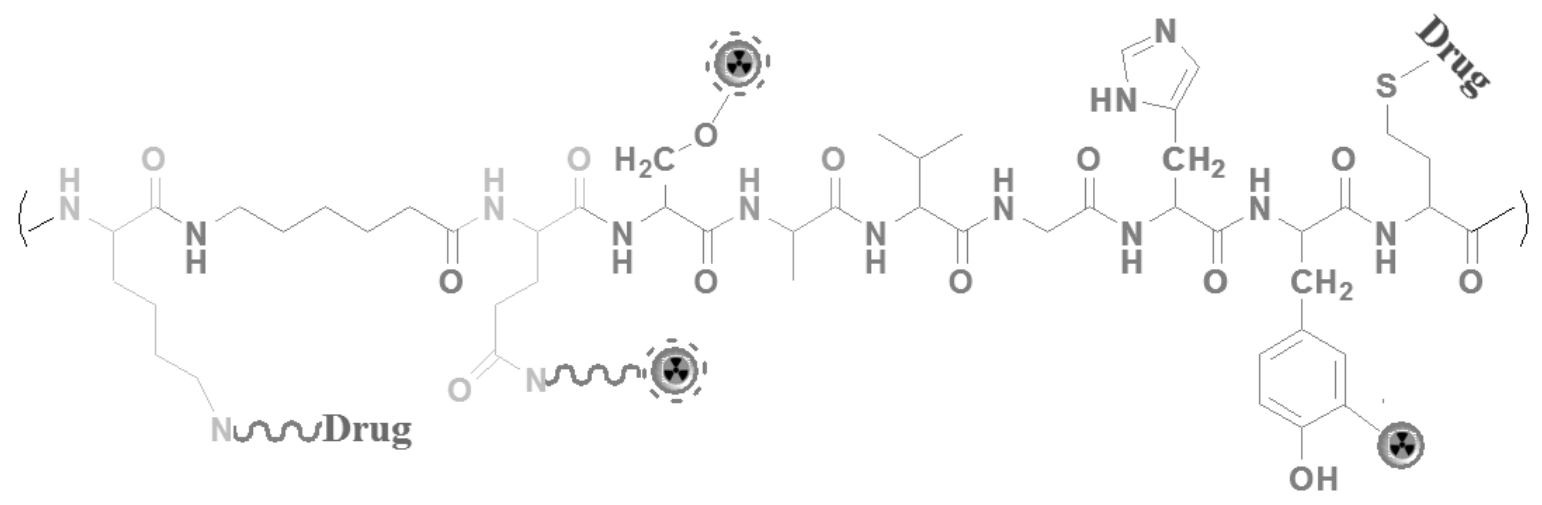

Figure 3. Peptides can covalently bind to radioiodine through Tyrosine or can bind to ${ }^{99 \mathrm{~m}} \mathrm{Tc}$ with special sequences directly or indirectly by linkers or chelator conjugation.

Conjugation with poly (styrene-co-maleic acid anhydride) (SMA) increases blood plasma circulation time through binding to albumin and decreases enzymatic degradation and immunogenicity similar to PEG. SMA conjugated neocarzinostatin has been recently approved in Japan for hepatoma treatment. Also dextran a $\mathrm{pH}$ sensitive, hygroscope and biodegradable polymer has been used in drug delivery (35). In 2006, Chau et al. designed a new dextranpeptide conjugated methotrexate (MTX) to achieve tumor-targeted delivery of MTX. They used two sequences of peptides as a linker between dextran and MTX. Histological studies in animal models demonstrated significant antitumor efficacy, but weight loss as a toxicity indicator was minor (36). Integrins as cell surface receptors to mediate adhesion between cells and the extracellular matrix (ECM), by binding to ligands with exposed arginine-glycineaspartate (RGD) sequence (cell adhesion motif). In 2010, Wang and Zhang et al. modified DOX - loaded liposome by RGD peptide to improve its anticancerefficacy. Indeed, laser confocal scanning microscopy (LCSM) detection, DOX cellular uptake and distribution have been enhanced by RGD modification in the three cell lines (B16, B16F10 and HUVEC) (37). In 2013, Wu et al. found that SP90 (H2N-SMDPFLFQLLQL-COOH) conjugated liposomal DOX increases the therapeutic index of the DOX by selective accumulation in tumor xenograft compared to normal organs. They concluded that the SP90 has significant potential in the chemotherapy and clinical diagnosis of breast cancer (38). There are many peptides which have been modified selectively to enhance in vivo stability and resistance against proteolytic degradation, especially for tumor cells. They have been labeled with different radionuclides for imaging by PET or SPECT (29). Bombesin (BBN) a neuropeptide with high affinity for gastrin-releasing peptide (GRP) receptors which are overexpressed in prostate, breast, and small-cell lung carcinoma, is 
radiolabeled with both ${ }^{99 \mathrm{~m}} \mathrm{Tc}$ and $18 \mathrm{~F}$ for prostate cancer imaging (39-41). In 2009, king et al. labeled three improved gastrin peptides with ${ }^{99 \mathrm{~m}} \mathrm{Tc}$ and their studies proved significant tumor uptake in micebearing AR42J tumor xenograft 1 hour after injection (42). Cyclic RGD is also labeled with ${ }^{99 \mathrm{~m}} \mathrm{Tc}$ for angiogenesis imaging (43).

\section{Nano systems}

There are some criteria for a polymer-drug conjugation: 1) biocompatibility and biodegradability of polymers; 2) Hydrophilicity of polymers backbone; 3) Chemical stability in plasma and 4) Low steric hindrance for drug covalent attachment facility and accessibility (38). The nanocarrier surface modification improves their pharmacokinetics, bioavailability, toxicity and customization of formulation (44). Nano systems may be quantum dots (QDs), super paramagnetic iron oxide nanoparticles (SPIONs), nanopolymers or biocompatible nanocarriers such as nanoliposomes which are more attractive for designing anticancer agents and radionuclides targeted delivery (Figure4).

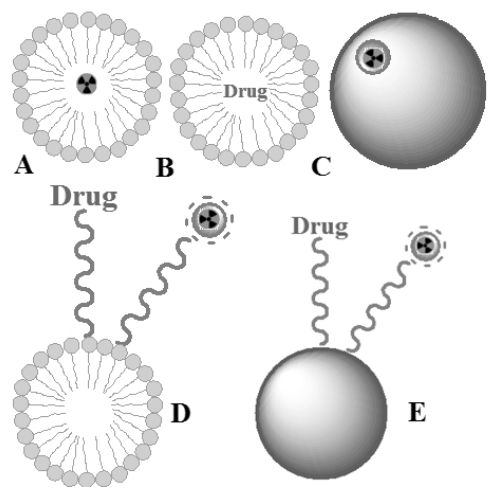

Figure 4. A: nanoliposomes encapsulated radioisotopes; B: nanoliposomes encapsulated chemotherapic agents; $\mathrm{C}$ : radioactive nanoparticles; D: nanoliposomes; and E: nanoparticles modified with cancer diagnostic and therapeutic agents.

Doxil ${ }^{\circledR}$ is DOX encapsulated nanoliposomes commercially available product which is the result of nano systems for targeted drug delivery system (45). Nanoparticles are usually trapped by reticuloendothelial system (RES) depending on their charge, hydrophobicity and size ranges. Particles with size $100 \mathrm{~nm}$ or less in diameter and hydrophilic surface cannot be cleared by macrophages thus they have longer circulation time in bloodstream, and hence have greater ability to target sites. Paclitaxel as microtubule polymerization stabilizer with severe side effects such as hypersensitive reactions, nephrotoxicity and neurotoxicity when encapsulated with Poly (lactic-co-glycolic) acid (PLGA) is released with very constant rate and over a long period of time (46). DOX, Docetaxel and some anticancer drugs have also been investigated by this controlled delivery (47). Platinum-based anticancer drugs coated with gold nanoparticles were functionalized with a thiolated poly (ethylene glycol) (PEG) monolayer and have been prepared to avoid dose-limiting side effects and possible drug resistance. IC50 in colon cancer cell lines (HCT116, HCT15, HT29, and RKO and human lung cancer cell line A549) exhibited more toxicity compared to oxaliplatin as control (48). Topotecan (TPT), a highly active camptothecin (CPT) and cytotoxic quinoline alkaloid which inhibits the DNA topoisomerase I has been encapsulated in nanoliposomes with acidic interior where the drug can be stabilized in the active lactone configuration. Tumor size decreased in human prostate (DU-145) and breast cancer (BT-474) xenograft models which confirmed in vivo efficacy and reliability of liposomal TPT (49). Nanotargeted radionuclides have also been designed for cancer nuclear imaging and internal radiotherapy. Auger electron, $\alpha, \beta$ and $\gamma$ radiation emitters have been used in chelating by surface modified nanosystems or encapsulating in flexible nanoliposomes (2, 50). Gold-198 $\left({ }^{198} \mathrm{Au}\right)$ nanoparticles are progressing in oncology and have some advantages due to synergistic molecular imaging and therapy properties. ${ }^{198} \mathrm{Au}$ is a mediumenergy $\beta$-emitter $\left(\beta_{\max }=0.96 \mathrm{MeV} ; \mathrm{T}_{1 / 2}=2.7\right.$ days with a $\gamma$-radiation at $0.411 \mathrm{MeV}$ ). In 2010 , Chanda et al. conjugated $\mathrm{BBN}$ peptide to both radioactive and non-radioactive gold nanoparticles (AuNPs). Intraperitoneal injection of modified AuNP-BBN in normal mice showed RES uptake is reduced however, it increased at tumor targets. They also observed a widespread uptake of BBN conjugated ${ }^{198}$ AuNPs in GRP-receptor-expressing pancreatic acini with maximum radioactivity after $4 \mathrm{~h}$ and slow clearance beyond 12 and 24h (51). Biological evaluation, both biodistribution and scintigraphic for ${ }^{99 \mathrm{~m}} \mathrm{Tc}$ nanoliposomes in healthy CD1 mice at 1 and 3 hours post injection demonstrated high liver uptake without pertinent accumulation in other organs (52). In 2004, Bao et al. labeled Pegylated Liposomal DOX with ${ }^{99 \mathrm{~m}}$ Tc directly using $\mathrm{N}, \mathrm{N}$-bis (2-mercapto-ethyl)-N, $\mathrm{N}$-diethyl-ethylenediamine (BMEDA). Scintigraphic images in normal rats with ${ }^{99 \mathrm{~m}} \mathrm{Tc}$-Doxil ${ }^{\circledR}$ in comparison with ${ }^{99 \mathrm{~m}}$ Tc-BMEDA alone depicted slow blood clearance in RES and the injected activity curve in blood dropped out less than 5 percent within 45 hours (53).

\section{Aptides}

The design and development of targeting ligand for diagnosis and therapy of human cancers has been investigated for several decades. "Aptides", from aptamer-like peptides, are composed of a stabilizing scaffold and two target binding regions. The scaffold 
consists of small but highly stable structure with two tryptophan zipper motifs like $\beta$-hairpin. The Sequence of scaffold with twelve amino acids is constant. Two target binding sites are comprised of six changeable amino acids that both ends of them connect to scaffold structure through glycine linkers. This novel class of high-affinity peptides has several advantages over large high-affinity molecules: with 26 amino acids (ca. $3 \mathrm{kDa}$ ), they can be synthesized in a single chemical process. Aptides are also much smaller than molecules such as antibodies (ca.150 $\mathrm{kDa}$ ), aptamers (ca. $>10 \mathrm{kDa}$ ) and protein scaffolds (ca.7-20 kDa). It has been demonstrated that smaller molecules result in higher accumulation in tumor than larger molecules with similar affinities because of rapid diffusion in tumors, when the sizes of both molecules are below a molecular weight cut off (ca.40 kDa) for renal excretion; higher affinity may lead to better tumor uptake (54). Fibronectin Extra Domain B (EDB), an alternatively spliced segment of fibronectin, is highly expressed in malignant tumors during angiogenesis and has been reported as an oncofetal cancer biomarker (55-57). In 2012, Sangyong Jon et al. designed the most favorable aptide (APTEDB) by using phage display and surface plasmon resonance (SPR) assay. Phage display technology can be used to identify peptide sequences which can particularly bind to tumor markers like molecular glue. In 2014, they conjugated APTEDB to docetaxel (DTX) and evaluated its targeting in tumor associated fibronectin. DTX was conjugated to APTEDB using click chemistry between an alkyne and an azide functional group to improve therapeutic efficacy and reduce adverse effects. DTX is a widely used anticancer drug that is effective in the treatment of various human malignancies. DTX has poor solubility in water but DTX conjugate can be carried out in aqueous media.

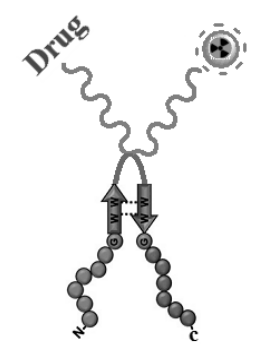

Figure 5. Aptides as novel antibody shaped and aptamer like peptides can promise well in targeted drug delivery.

The lack of its tissue specificity, leads to adverse side effects such as hematological toxicity. In vitro and in vivo studies demonstrated that APTEDB conjugated DTX is more effective in cancer therapy of EDBoverexpressing tumors with much lower toxicity than the free drug. Murine LLC and human U373MG cell lines were used as EDB positive and negative cancer cells, respectively. APTEDB-DTX (5mg DTX/kg) effectively suppressed tumor growth compared to that observed in the control group (58). Different biologically important specific aptides have been also screened by phage-display.In 2013, Sangyong Jon et al. prepared HER2-specific-aptide-conjugated magneto-nanoclusters for cancer imaging as well as targeted therapy (59). Radiolabeling of aptides whether directly or by bifunctional chelating agents (BFCA) is a promising method for targeted cancer imaging intermediation (Figure 5).

\section{Conclusion}

Aptides are suitable candidates for tumor imaging and therapy, because they are small, high- affinity peptides with affinities in the nanomolar range with slow dissociation rates. In addition unlike antibodies or proteins, aptides are amenable to site-specific conjugation with variety of molecules like anticancer drugs for targeted therapy and biopharmaceutical applications without immunogenicity and imaging techniques during peptide synthesis, as expanding the range of potential applications. Altogether, the potential applications of novel aptide technology span the full range of biopharmaceutical applications, from biological research and diagnostics to therapeutics, including the direct development of peptide drugs.

In this mini review, we deduce that each plot has some advantages as well as also disadvantages. Even the integration of two or more delivery systems to improve the defects causes new disabilities. Challenges in targeted drug delivery in cancer diagnosis and treatment have not been removed so far.

\section{Author Contribution}

MM contributed to researching data and writing the draft, RF editing the manuscript and SN making study design, review, revise and editing the manuscript. All authors read and approved the final manuscript.

\section{References}

1. Aerts A, Impens NREN, Gijs M, D'Huyvetter M, Vanmarcke H, Ponsard B, et al. Biological carrier molecules of radiopharmaceuticals for molecular cancer imaging and targeted cancer therapy. Curr Pharm Des. 2014; 20: 5218-5244. PMID: 24606796

2. Ting G, Chang $\mathrm{CH}$, Wang HE, Lee TW. Nanotargeted radionuclides for cancer nuclear imaging and internal radiotherapy. J. Biomed. Biotechnol. 2010; 2010: 1-14. PMID: 20811605

3. Chopra D. Radiolabelled Nanoparticles for Diagnosis and Treatment of Cancer: INTECH Open Access Publisher 2010: pp225-240 
4. Kumar SR, Deutscher SL. 111In-labeled galectin-3-targeting peptide as a SPECT agent for imaging breast tumors. J Nucl Med. 2008; 49: 796-803. PMID: 18413389

5. Faintuch BL, Teodoro R, Duatti A, Muramoto E, Faintuch S, Smith CJ. Radiolabeled bombesin analogs for prostate cancer diagnosis: preclinical studies. Nucl Med Biol. 2008; 35: 401-411. PMID: 18482672

6. Sudimack J, Lee RJ. Targeted drug delivery via the folate receptor. Adv. Drug Delivery Rev. 2000; 41: 147-162. PMID: 10699311

7. Van de Wiele C, Dumont F, Dierckx RA, Peers SH, Thornback JR, Slegers G, et al. Biodistribution and dosimetry of $99 \mathrm{mTc}-$ RP527, a gastrin-releasing peptide (GRP) agonist for the visualization of GRP receptor-expressing malignancies. J Nucl Med. 2001; 42: 1722-7. PMID: 11696645

8. Li L, Wartchow CA, Danthi SN, Shen Z, Dechene N, Pease J, et al. A novel antiangiogenesis therapy using an integrin antagonist or anti Flk-1 antibody coated 90 Y-labeled nanoparticles. Int J Radiat Oncol Biol Phys. 2004; 58: 1215-7. PMID: 15001266

9. Kim E-M, Joung M-H, Lee C-M, Jeong H-J, Lim ST, Sohn M$\mathrm{H}$, et al. Synthesis of Tc-99m labeled 1, 2, 3-triazole-4-yl c-met binding peptide as a potential c-met receptor kinase positive tumor imaging agent. Bioorg. Med. Chem lett. 2010; 20: 4240-3. PMID: 20538463

10. Fahmy TM, Fong PM, Goyal A, Saltzman WM. Targeted for drug delivery. Mater Today. 2005; 8: 18-26.

11. Tani Y, Nakajima M, Kikuchi M, Ihara K, Muroi H, Takahashi $\mathrm{M}$, et al. 18F-Fluorodeoxyglucose Positron Emission Tomography for Evaluating the Response to Neoadjuvant Chemotherapy in Advanced Esophageal Cancer. Anticancer Res. 2016; 36: 367-3. PMID: 26722067

12. Fujii $T$, Yajima $R$, Tatsuki $H$, Oosone $K$, Kuwano $H$ Implication of 18F-Fluorodeoxyglucose Uptake of Affected Axillary Lymph Nodes in Cases with Breast Cancer. Anticancer Res. 2016; 36: 393-397. PMID: 26722071

13. Lambert JM. Drug-conjugated monoclonal antibodies for the treatment of cancer. Curr Opin Pharmacol. 2005; 5: 543-549. PMID: 16087399

14. Harris M. Monoclonal antibodies as therapeutic agents for cancer. Lancet Oncol. 2004; 5: 292-302. PMID: 1512066

15. Teicher BA, Chari RVJ. Antibody conjugate therapeutics: challenges and potential. Clin Cancer Res. 2011; 17: 6389-7. PMID: 22003066

16. Alley SC, Okeley NM, Senter PD. Antibody-drug conjugates: targeted drug delivery for cancer. Curr Opin Chem Biol. 2010; 14: 529-37. PMID :20643572

17. Senter PD, Springer CJ. Selective activation of anticancer prodrugs by monoclonal antibody-enzyme conjugates. Adv. Drug Delivery Rev. 2001; 53: 247-64. PMID: 11744170

18. Hamblett KJ, Senter PD, Chace DF, Sun MMC, Lenox J, Cerveny CG, et al. Effects of drug loading on the antitumor activity of a monoclonal antibody drug conjugate. Clin. Cancer Res. 2004; 10: 7063-70. PMID: 15501986

19. Kuroda K, Liu H, Kim S, Guo M, Navarro V, Bander NH. Saporin toxin-conjugated monoclonal antibody targeting prostate- specific membrane antigen has potent anticancer activity. Prostate. 2010; 70: 1286-94. PMID: 20623630

20. Wang S, Noberini R, Stebbins JL, Das S, Zhang Z, Wu B, et al. Targeted delivery of paclitaxel to EphA2-expressing cancer cells. Clin. Cancer Res. 2013; 19: 128-37. PMID: 23155185

21. Cheng WW, Allen TM. The use of single chain Fv as targeting agents for immunoliposomes: an update on immunoliposomal drugs for cancer treatment. Expert Opin Drug Deliv. 2010; 7: 46178. PMID: 20331354

22. Ray P, White RR. Aptamers for targeted drug delivery. Pharmaceuticals 2010; 3: 1761-78. PMID: 27713328

23. Bagalkot V, Zhang L, Levy-Nissenbaum E, Jon S, Kantoff PW, Langer R, et al. Quantum dot-aptamer conjugates for synchronous cancer imaging, therapy, and sensing of drug delivery based on bifluorescence resonance energy transfer. Nano Lett. 2007; 7: 306570. PMID: 17854227

24. Bagalkot V, Farokhzad OC, Langer R, Jon S. An AptamerDoxorubicin Physical Conjugate as a Novel Targeted DrugDelivery Platform. Angew Chem Int Ed Engl. 2006; 45: 8149-52. PMID: 17099918

25. Huang YF, Shangguan D, Liu H, Phillips JA, Zhang X, Chen $\mathrm{Y}$, et al. Molecular assembly of an aptamer-drug conjugate for targeted drug delivery to tumor cells. Chembiochem. 2009; 10: 862-8. PMID: 19253992

26. Hao Z, Fan W, Hao J, Wu X, Zeng GQ, Zhang LJ, et al. Efficient delivery of micro RNA to bone-metastatic prostate tumors by using aptamer-conjugated atelocollagen in vitro and in vivo. Drug Deliv. 2014: 1-8. PMID: 24892627

27. Hicke BJ, Stephens AW, Gould T, Chang Y-F, Lynott CK, Heil J, et al. Tumor targeting by an aptamer. J Nucl Med. 2006; 47: 668-8. PMID: 16595502

28. Mansi R, Fleischmann A, Mäcke HR, Reubi JC. Targeting GRPR in urological cancers-from basic research to clinical application. Nat Rev Urol. 2013; 10: 235-44. PMID: 23507930

29. Fani M, Maecke HR, Okarvi SM. Radiolabeled peptides: valuable tools for the detection and treatment of cancer. Theranostics. 2012; 2: 481. PMID: 22737187

30. Khan IU, Zwanziger D, Böhme I, Javed M, Naseer H, Hyder SW, e al. Breast-Cancer Diagnosis by Neuropeptide Y Analogues: From Synthesis to Clinical Application. Angew Chem Int Ed. 2010; 49: 1155-8. PMID: 20104470

31. Van Hensbergen Y, Broxterman HJ, Elderkamp YW, Lankelma J, Beers JCC, Heijn M, Boven E, Hoekman K, Pinedo HM. A doxorubicin-CNGRC-peptide conjugate with prodrug properties. Biochem Pharmacol. 2002; 63: 897-908.PMID: 11911842

32. Ranieri G, Patruno R, Ruggieri E, Montemurro S, Valerio P, Ribatti D. Vascular endothelial growth factor (VEGF) as a target of bevacizumab in cancer: from the biology to the clinic. Curr Med Chem. 2006; 13: 1845-57. PMID:16842197

33. Askoxylakis V, Zitzmann S, Mier W, Graham K, Krämer S, von Wegner $\mathrm{F}$, et al. Preclinical evaluation of the breast cancer cell-binding peptide, p160. Clin Cancer Res. 2005; 11: 6705-12. PMID: 16166451

34. Lu Z-R, Shiah J-G, Sakuma S, Kopečková P, Kopeček J. Design of novel bioconjugates for targeted drug delivery. J Control 


\section{Release 2002; 78: 165-73. PMID: 11772458}

35. Torchilin VP, Lukyanov AN. Peptide and protein drug delivery to and into tumors: challenges and solutions. Drug Discov Today 2003; 8: 259-66. PMID: 12623240

36. Chau Y, Padera RF, Dang NM, Langer R. Antitumor efficacy of a novel polymer-peptide-drug conjugate in human tumor xenograft models. Int J Cancer. 2006; 118: 1519-26. PMID: 16187287

37. Xiong X-B, Huang Y, Lu W-L, Zhang X, Zhang H, Nagai T, et al. Intracellular delivery of doxorubicin with RGD-modified sterically stabilized liposomes for an improved antitumor efficacy: In vitro and in vivo. J Pharm Sci. 2005; 94: 1782-3. PMID: 15986461

38. Lu R-M, Chen M-S, Chang D-K, Chiu C-Y, Lin W-C, Yan S$\mathrm{L}$, et al. Targeted drug delivery systems mediated by a novel Peptide in breast cancer therapy and imaging. PLoS One. 2013; 8: e66128. PMID: 23776619

39. Li Z-B, Wu Z, Chen K, Ryu EK, Chen X. 18F-labeled BBNRGD heterodimer for prostate cancer imaging. J Nucl Med. 2008; 49: 453-61. PMID: 23776619

40. Sadeghzadeh N, Gandomkar M, Shafiee M, Mazidi M, Goudarzi M, Mirfallah SH, et al. Synthesis and evaluation of a new radiolabeled bombesin analogue for diagnosis of GRP receptor expressing tumors. Iran J Nucl Med. 2009; 17: 18-26.

41. Sadeghzadeh N, Gandomkar M, Najafi R, Shafiei M, Ebrahimi SES, Shafiee A, et al. Preparation and evaluation of a new $99 \mathrm{mTc}$ labeled bombesin derivative for tumor imaging. J Radioanal Nucl Chem. 2010; 283: 181-187.

42. King R, Surfraz MB-U, Finucane C, Biagini SCG, Blower PJ, Mather SJ. 99mTc-HYNIC-gastrin peptides: assisted coordination of $99 \mathrm{mTc}$ by amino acid side chains results in improved performance both in vitro and in vivo. J Nucl Med. 2009; 50: 591598. PMID: 19289435

43. Tsiapa I, Loudos G, Varvarigou A, Fragogeorgi E, Psimadas D, Tsotakos T, et al. Biological evaluation of an ornithine-modified 99mTc-labeled RGD peptide as an angiogenesis imaging agent. Nucl Med Biol. 2013; 40: 262-72. PMID: 23238128

44. Ting G, Chang C-H, Wang H-E. Cancer nanotargeted radiopharmaceuticals for tumor imaging and therapy. Anticancer Res. 2009; 29: 4107-18. PMID:19846958

45. Barenholz YC. Doxil®-the first FDA-approved nano-drug: lessons learned. J. Controlled Release. 2012; 160: 117-34. PMID: 22484195

46. Dinarvand R, Sepehri N, Manoochehri S, Rouhani H, Atyabi F. Polylactide-co-glycolide nanoparticles for controlled delivery of anticancer agents. Int J Nanomedicine. 2011; 6: 877-95. PMID: 21720501

47. Patil R, Portilla-Arias J, Ding H, Konda B, Rekechenetskiy A, Inoue $\mathrm{S}$, et al. Cellular delivery of doxorubicin via $\mathrm{pH}$-controlled hydrazone linkage using multifunctional nano vehicle based on poly ( $\beta$-L-malic acid). Int J Mol Sci. 2012; 13: 11681-93. PMID: 23109877
48. Brown SD, Nativo P, Smith J-A, Stirling D, Edwards PR, Venugopal B, et al. Gold nanoparticles for the improved anticancer drug delivery of the active component of oxaliplatin. J Am Chem Soc. 2010; 132: 4678-84. PMID: 20225865

49. Drummond DC, Noble CO, Guo Z, Hayes ME, ConnollyIngram C, Gabriel BS, et al. Development of a highly stable and targetable nanoliposomal formulation of topotecan. J Controlled Release 2010; 141: 13-21. PMID: 19686789

50. Brannon-Peppas L, Blanchette JO. Nanoparticle and targeted systems for cancer therapy. Adv Drug Deliv Rev. 2012; 64: 206212

51. Chanda N, Kattumuri V, Shukla R, Zambre A, Katti K, Upendran A, et al. Bombesin functionalized gold nanoparticles show in vitro and in vivo cancer receptor specificity. Proc Natl Acad Sci U S A. 2010; 107: 8760-65. PMID: 20410458

52. Navarro G, Cabral P, Cabrera M, Fernández M, Gambini JP, Malanga A, et al. 99mTc-labeling and biological evaluation of conventional liposomes. ALASBIMN J. 2011; 13: 1-8.

53. Bao A, Goins B, Klipper R, Negrete G, Phillips WT. Direct $99 \mathrm{mTc}$ labeling of pegylated liposomal doxorubicin (Doxil) for pharmacokinetic and non-invasive imaging studies. J. Pharmacol. Exp. Ther. 2004; 308: 419-25. PMID: 14610219

54. Kim S, Kim D, Jung HH, Lee I-H, Kim JIL, Suh J-Y, Jon S. Bio-Inspired Design and Potential Biomedical Applications of a Novel Class of High-Affinity Peptides. Angew Chem Int Ed. 2012; 51: 1890-4. PMID: 22271427

55. Kaspar M, Zardi L, Neri D. Fibronectin as target for tumor therapy. Int J Cancer. 2006; 118: 1331-9. PMID: 16381025

56. Nilsson F, Kosmehl H, Zardi L, Neri D. Targeted delivery of tissue factor to the ED-B domain of fibronectin, a marker of angiogenesis, mediates the infarction of solid tumors in mice. Cancer Res. 2001; 61: 711-16. PMID: 11212273

57. Passarella RJ, Zhou L, Phillips JG, Wu H, Hallahan DE, Diaz $\mathrm{R}$. Recombinant peptides as biomarkers for tumor response to molecular targeted therapy. Clin Cancer Res. 2009; 15: 6421-9. PMID: 19825959

58. Kim H, Lee Y, Lee I-H, Kim S, Kim D, Saw PE, et al. Synthesis and therapeutic evaluation of an aptide-docetaxel conjugate targeting tumor-associated fibronectin. J Controlled Release. 2014; 178: 118-24. PMID: 24462899

59. Park J, Park S, Kim S, Lee I-H, Saw PE, Lee K, et al. HER2specific aptide conjugated magneto-nanoclusters for potential breast cancer imaging and therapy. J Mater Chem B 2013; 1: 45764583. 